\title{
Look-up table based fuzzy controller in order to control steaming room process
}

Controlador difuso basado en la tabla de búsqueda para controlar el

proceso de la sala de vapor

Autor:

Sadegh Aminifar ${ }^{(1)}$

Sirwan Mohamad Kekshar ${ }^{(2)}$

Muhammadamin Daneshwar ${ }^{(3)}$

\section{ARTÍCULO DE INVESTIGACIÓN CIENTÍFICA Y TECNOLÓGICA}

How to cite this paper:

Aminifar. S., Kekshar. S. M., Daneshwar. M., Look-up table based fuzzy controller in order to control steaming room process. Innovaciencia Facultad de Ciencias Exactas, Naturales y Agropecuarias. 2018; 6(1) S1: 1-12.

Reception date:

Received: 15 August 2018

Accepted: 25 November 2018

Published Online: 28 December 2018

DOI:

http:/ /dx.doi.org/10.15649/2346075X.486

Keywords:

Look-Up Table; Fuzzy; Temperature; Valve; Duration controllers.

\section{ABSTRACT}

Introduction: In this paper, using look-up table control strategy, a fuzzy logic controller is designed for controlling the temperature of steaming room in terrazzo tile plant corresponding to dedicated process diagrams. Methods: In the proposed method, the temperature and error of temperature are considered as inputs to control the duration of valve open time to decrease the activation times of valves in order to increase their longevity. The strategy considers an off-line trained look-up table for setting the time of opening valve in the specific temperature. A fuzzy controller with fifteen extracted rules is designed for controlling the duration of valve open time. Results: Results show that the number of switching of valve reduces compare to intuitionistic or expert rule extraction. Conclusions: Simulations provide more compatible steaming process rout compare to PID controllers.

Dr. Sadegh Aminifar, Department of Computer Science, Faculty of Science, University of Soran, e-mail: sadiq.aminifar@soran.edu.iq

(2) MSc. Sirwan Mohamad Kekshar, Department of Computer Science, Faculty of Science, University of Soran, e-mail: mershefa@gmail. com.

3s Assist. Prof. Dr. Muhammadamin Daneshwar, Department of Computer Science, Faculty of Science, University of Soran, e-mail mdaneshwar@gmail.com. 
INTRODUCCTION

For tile manufactures, the strength of tiles is very important. Following the process curve is provide by better controlling of steaming room. The quality of product after choosing composition of proper raw material and preparing enough pressure depends on the method of designing controller and extraction of rules.

Three characters which are important regarding these controllers are nonlinearity and unclearness: Nonlinearity and ill system definition is a challenge in various industrial plants (1). Steaming room and similar industrial plants suffer lack of well-defined mathematical model. Usually, designers simplify such systems by ignoring a lot of main parameters. On the other hand, a wide-spread problem in on-off and proportional valves which causes lower durability of industrial valves is static friction. Proportional valves are found everywhere in control industrial systems (2). On of challenges which recently focused on by scientists is valve stiction detection (3). (4). Normally, there is variation of threshold voltage in industrial valves which causes hysteresis ${ }^{-(5)}$. This paper proposes a fuzzy controller extracted by look-up table to reduce number of activation times of industrial valves. In this research, it is considered that the hysteresis model is defined in advance. The proposed controller controls the autoclave temperature by controlling the time duration that valve is open ${ }^{(6)}$.

It is applied fuzzy controller to specific industrial environment to overcome high nonlinearity ambiguity (7). Todays, designing trends are toward data based extraction compare to expert based system definition. Because, in dynamic systems, measuring high number of data helps to extracting a well-defined structure which is more compatible with the process.

An expert expresses the situation by several simple rules, but using look-up table usually clarifies that still more than experts discover about a system ${ }^{(8)}$. In case of subconscious level of expressing a system, the system is considered as a black box. The expert only specifies a short demonstration of the main system behaviors. But, we can use measured data pairs for extracting rules. Look-up table exactly, is that system which provides a routine process for extracting the effective rules between total possible rules $\stackrel{(9)}{~}$.

\section{MATERIALS AND METHOD}

\section{Measured Data Pairs and applying Look-Up Table method}

There are a set of input and output measured data, the main aim is to design a fuzzy rule-based controller considering of presence of $\mathrm{N}$ input-output pairs. For achieving this goal there are 5 steps which is proposed by Wang $\frac{(10)}{}$.

\section{Step 1: A specific number of fuzzy sets with equal supports divide all input and output universe of discourse.}

If our input is located between of $\mathrm{x} 0$ and $\mathrm{xn}$, and output is located between y0 and yn, the $\mathrm{N}$ fuzzy sets are assigned for $\mathrm{X}$ and $\mathrm{N}$ fuzzy sets are assigned for $\mathrm{Y}$.

For example, there is a measured data pairs shown in below table. It is divided the input and output range to two equal triangular fuzzy sets shown in below shape (the membership functions are all triangular). 
Table 1: An example of Input and Output data

\begin{tabular}{cc}
$\mathbf{X}$ (Input) & Y(Output) \\
1 & 2 \\
2 & 4 \\
3 & 5 \\
4 & 3 \\
5 & 8 \\
6 & 3 \\
7 & 0 \\
8 & 9 \\
9 & 9 \\
10 & 10 \\
\hline
\end{tabular}
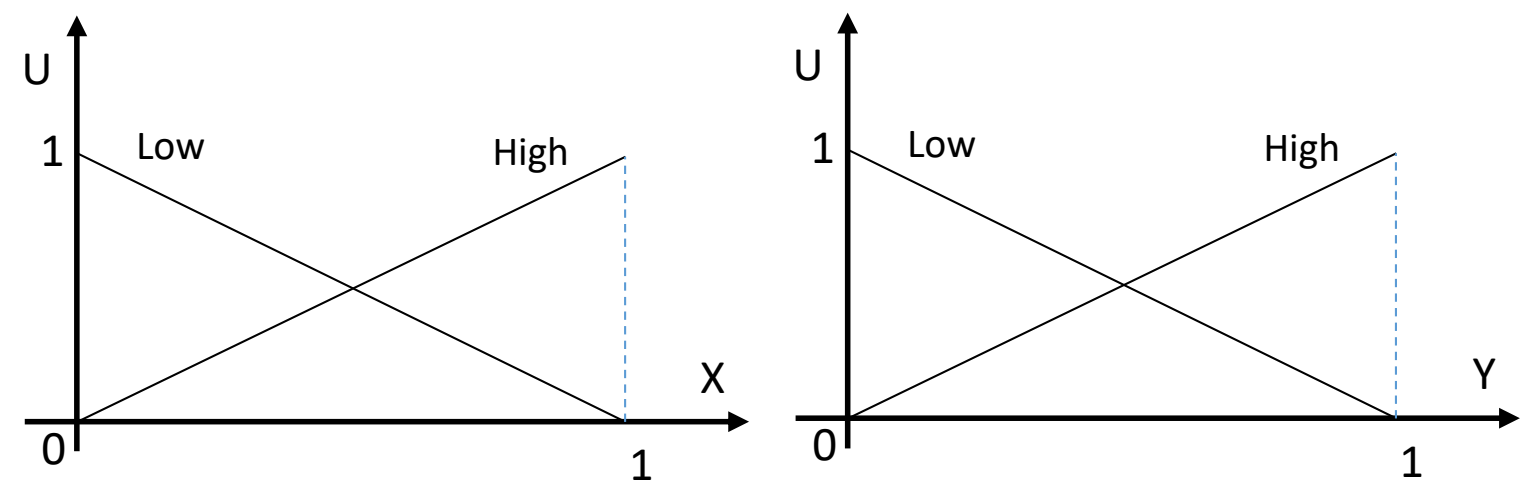

Figure 1: Dedicated Membership Functions

\section{Step 2. Rule description for each pair of input and outputs.}

For all $\mathrm{X}$ numbers in above table, the membership degrees are calculated based on considered membership functions. The same thing is done for $\mathrm{Y}$ numbers of the table. Each membership in X side is considered as an antecedent of a rule. On the other hand, each Y membership function in $\mathrm{Y}$ side is considered as consequent of the same rule. For example, there are four possible rules for above structure:

- If $\mathrm{x}$ is low then $\mathrm{Y}$ is low Rule:1

- If $\mathrm{x}$ is low then $\mathrm{Y}$ is High Rule:2

- If $\mathrm{x}$ is High then $\mathrm{Y}$ is low Rule:3

- If $x$ is High then $Y$ is High Rule:4 


\section{Step 3: All rules take a validation value.}

Each rule must evaluated for each data pairs. The evaluation degree of each rule is calculated by multiplying corresponding membership degrees of $\mathrm{X}$ and $\mathrm{Y}$.

$\mathrm{P}$ in below formula calculates the power of each rule:

$\mathrm{P}($ rule $)==\sum_{i=1}^{n} \mu \mathrm{A}_{i}^{j}=\left(\mathrm{x}_{0 j}^{p}\right) \mu B^{i *}\left(\mathrm{y}_{0}^{p}\right)$

Now, conflicting rules are omitted. What is conflicting rules: The rules with the same antecedent may activate with different activation degrees. In this case, the rule with lower activation degrees are omitted. The rules with higher activation degree are winners. Sometimes, human expert may interfere to omit a rule with higher activation degree or maintain a specific rule with lower activation degree.

Selecting the maximum degree of membership for each rule and choosing the maximum amount of membership rating for each rule via below calculations:

Table 2: Power of Rules Calculations

\begin{tabular}{lcccccccc} 
Available Points & ULX & UHX & ULY & UHY & Rule 1 & Rule 2 & Rule 3 & Rule 4 \\
P1: $(1,2)$ & 0.9 & 0.1 & 0.8 & 0.2 & 0 & 0 & 0 & 1 \\
P2: $(2,4)$ & 0.8 & 0.2 & 0.6 & 0.4 & 0.02 & 0.08 & 0.18 & 0.72 \\
P3: $(3,5)$ & 0.7 & 0.3 & 0.5 & 0.5 & 0.08 & 0.12 & 0.32 & 0.48 \\
P4: $(4,3)$ & 0.6 & 0.4 & 0.7 & 0.3 & 0.15 & 0.15 & 0.35 & 0.35 \\
P5: $(5,8)$ & 0.5 & 0.5 & 0.2 & 0.8 & 0.12 & 0.28 & 0.18 & 0.42 \\
P6: $(6,3)$ & 0.4 & 0.6 & 0.7 & 0.3 & 0.40 & 0.10 & 0.40 & 0.10 \\
P7: $(7,0)$ & 0.3 & 0.7 & 1 & 0 & 0.18 & 0.42 & 0.12 & 0.28 \\
P8: $(8,9)$ & 0.2 & 0.8 & 0.1 & 0.9 & 0 & 0.7 & 0 & 0.3 \\
P9: $(9,9)$ & 0.1 & 0.9 & 0.1 & 0.9 & 0.72 & 0.08 & 0.18 & 0.02 \\
P10: $(10,10)$ & 0 & 1 & 0 & 1 & 0.81 & 0.09 & 0.09 & 0.01 \\
The power of each rule & & & & & $\mathbf{3 . 4 8}$ & $\mathbf{2 . 0 2}$ & $\mathbf{1 . 8 2}$ & $\mathbf{3 . 6 8}$ \\
\hline
\end{tabular}

\section{Step 4: Rule Extraction.}

Non-conflicting rules are chosen as main part of the rule base. The other parts of rules are chosen between conflicting rules. The method of selecting conflicting rules are based on the fact that higher activation degree rule is the winner. The third part of selected rules are the rules which are selected by human expert between total conflicting rules based on environmental information he/she has.

Assign degrees to rules and choose the maximum amount of rules and eliminate conflicting rules choose the maximum amount of rules and eliminate conflicting rules. 
Choosing Rules: According to Table 2, two rules win the process.

Table 3: List of rules with maximum power
Rule: 2
If $x$ is low then $Y$ is High
Rule: 3
If $x$ is High then $Y$ is low

\section{Step 5: Using extracted rules for constructing the desired fuzzy controller}

Each fuzzy system has a rule base and three main blocks fuzzifier, Inference motor and defuzzifier block. There are several methods for implication that we can use as main operator in inference block such as min and product. Our option in this research is Min operator. Between various defuzzification methods, center of gravity is chosen.

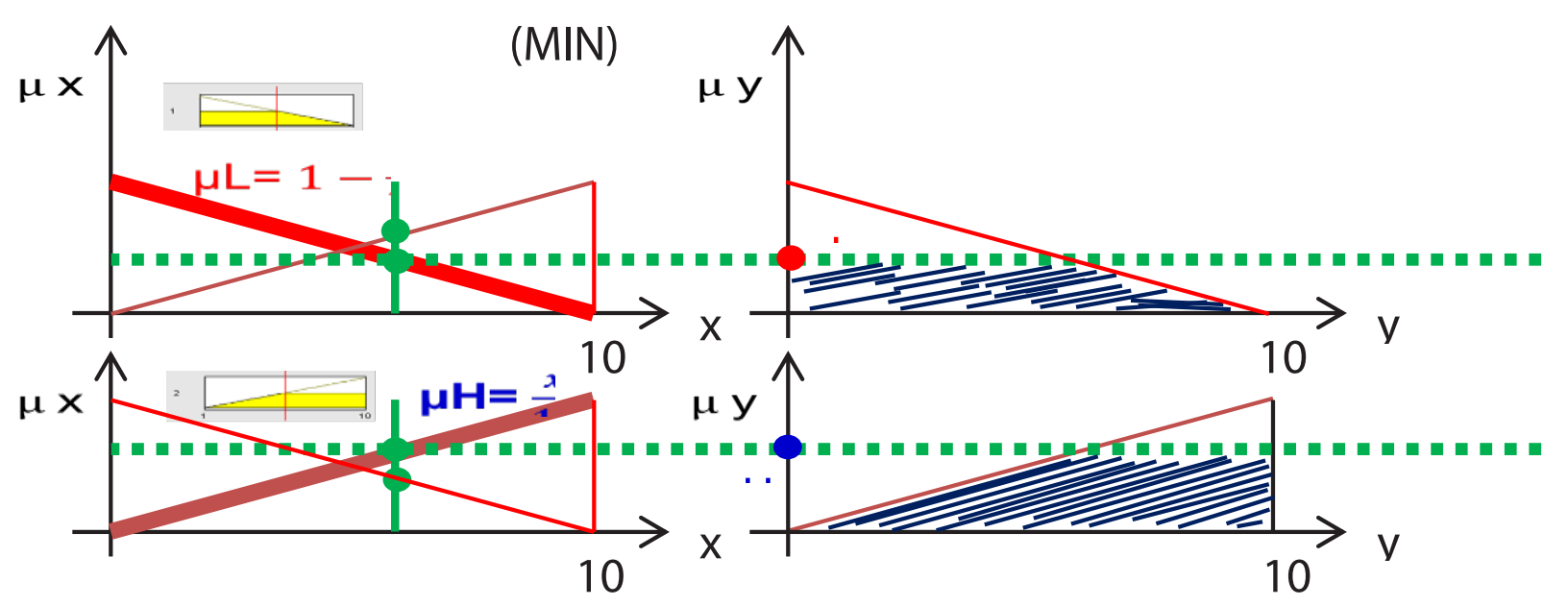

Figure 2: Calculation of activation degree

As a one fast tool in MATLAB, the research used ANFIS to tool, as well as look-up table for extracting rules and make a comparison between them. The artificial neural fuzzy inference system technique called artificial neural networks (ANFIS). ANFIS falls under the umbrella of artificial intelligence. ANFIS approximate the structure of the human brain based on making some decision functions. The human brain performs functions in a parallel processing method. Therefore the brain is capable of handling complex task in comparison with computers. In contrast, digital computers are very fast in many cases $\stackrel{(11)}{\text {. }}$ 
Create a Fuzzy Rules and Fuzzy System Base Draw a chart by selecting a desired point:
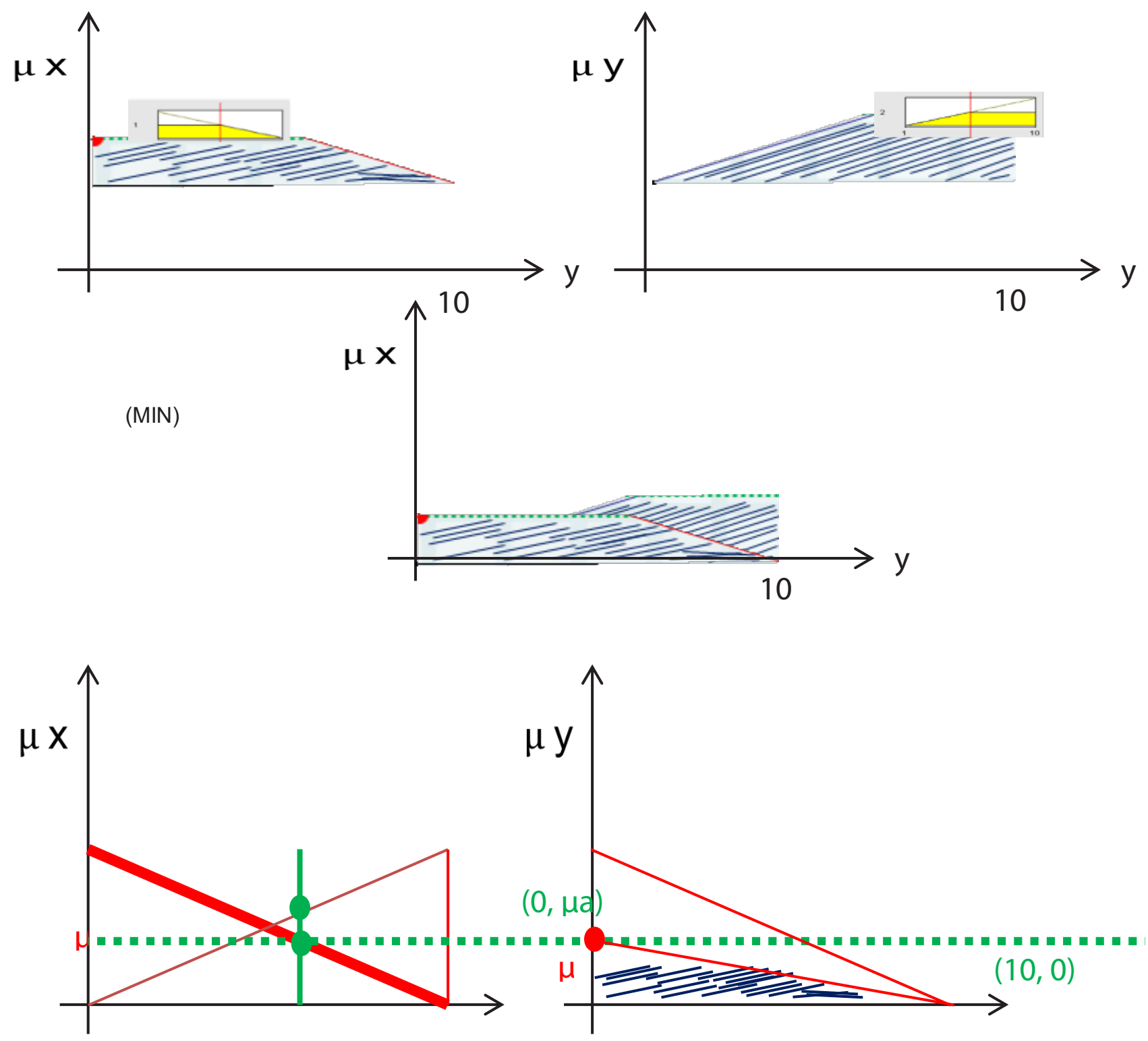

$$
\begin{gathered}
(0, \mu a) \longrightarrow(10,0) \\
\frac{\mu L-0}{y-10}=\frac{\mu a-0}{0-10} \longrightarrow \mu L=-\frac{\mu a}{10}(y-10)
\end{gathered}
$$

Figure 3: Centre of gravity 
Create a Fuzzy Rules and Fuzzy System Base Draw a chart by selecting a desired point:

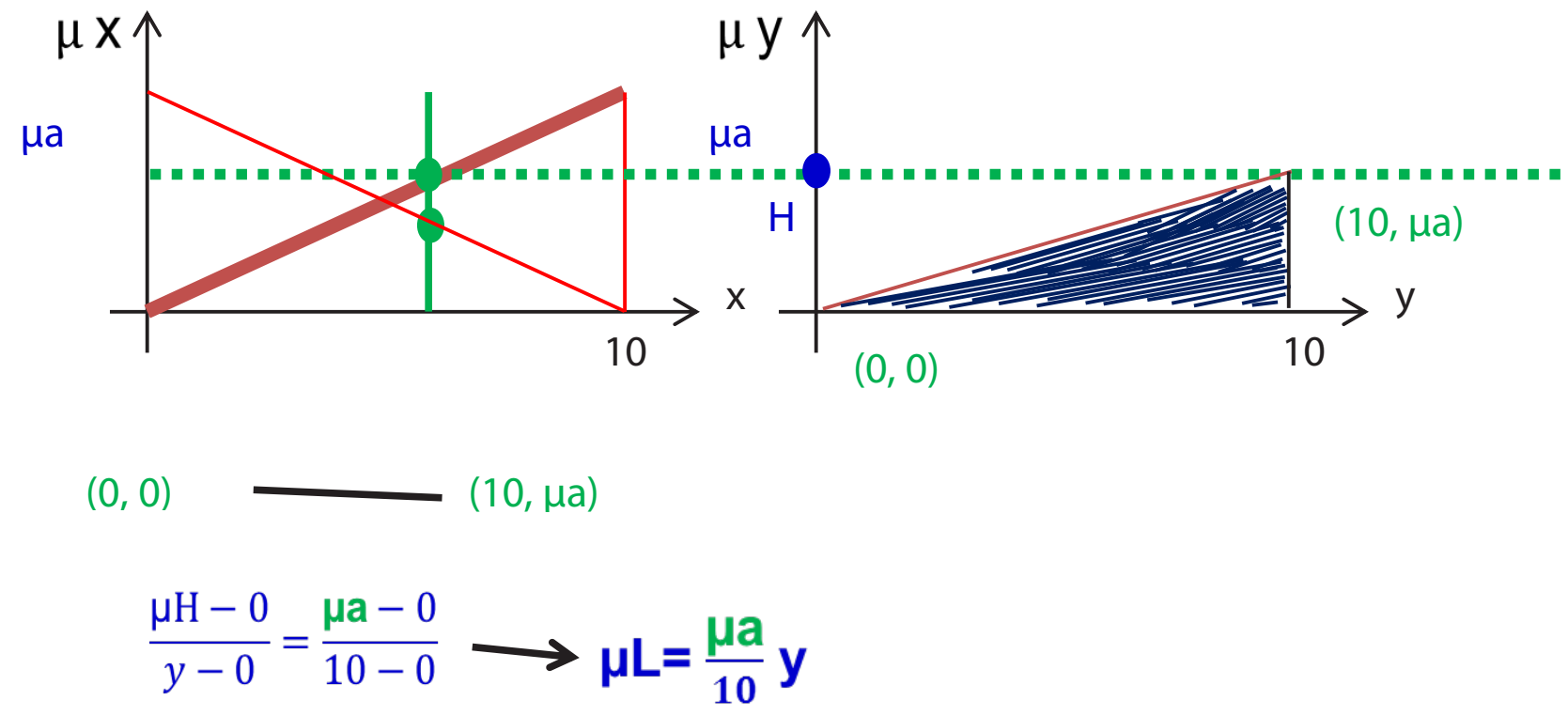

Figure 4: Product-sum defuzzifying

Create a fuzzy rules and fuzzy system base using the center of gravity for defuzzification:

$$
\begin{aligned}
& \mathrm{Y}=\frac{\int \mu \mathrm{L} * y+\mu \mathrm{H} * y d y}{\int \mu \mathrm{L}+\mu \mathrm{H} d y}=\frac{\int-\frac{\mu \mathrm{a}}{10}(\mathrm{y}-10) * \mathrm{y}+\frac{\mu \mathrm{a}}{10} y * \mathrm{y} d y}{\int-\frac{\mu \mathrm{a}}{10}(\mathrm{y}-10)+\frac{\mu \mathrm{a}}{10} \mathrm{y} d \mathrm{y}} \\
& =\frac{\int \mu \mathrm{ay} d y}{\int \mu \mathrm{a} d \mathrm{y}}=\left[\frac{1}{2} y\right]=5
\end{aligned}
$$

Extracting the rule base of applied fuzzy controller

A type one fuzzy controller, based on above described knowledge and simulations is designed for applying to steaming room. Input of the controller is the temperature. The universe of discourse of real measured temperature is divided between three triangular membership functions which they overlap each other symmetrically.

The output of the controller is the activation time of the valve. The interval of time activation is -166 to 166 which is divided between five equal and symmetric triangular membership functions $\stackrel{(12)}{~}$. 


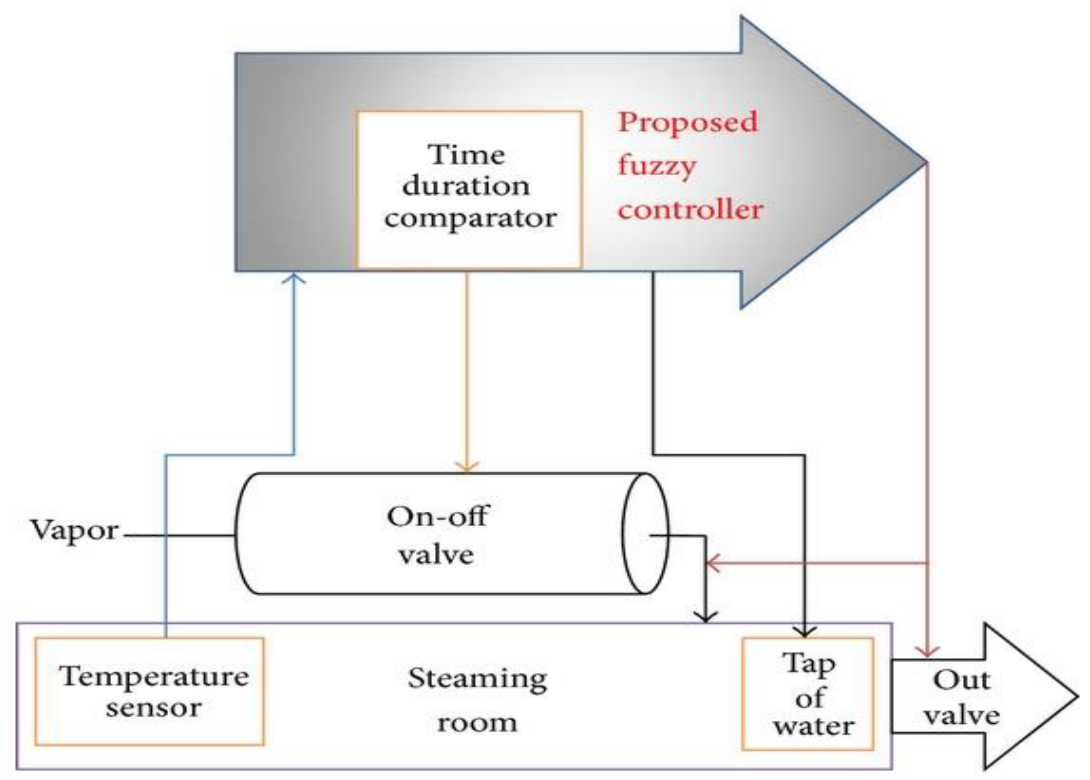

Figure 5: Under control system
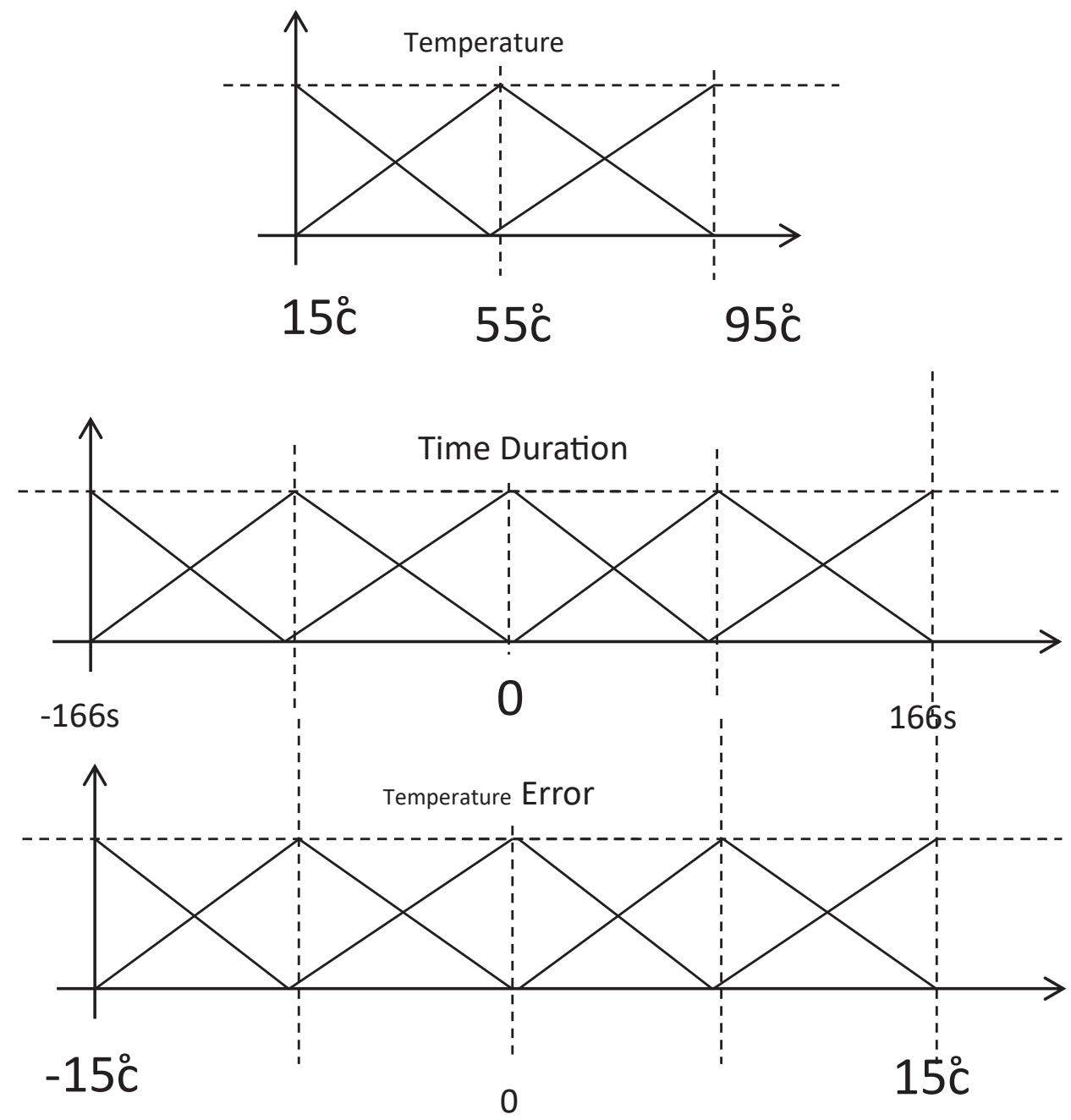

Figure 6: Assigned Membership Functions 
The number of all possible rules are $45(3 * 5 * 3)$. Using Look-up method 15 rules are extracted. The control surface of proposed controller is shown in Figure 7.

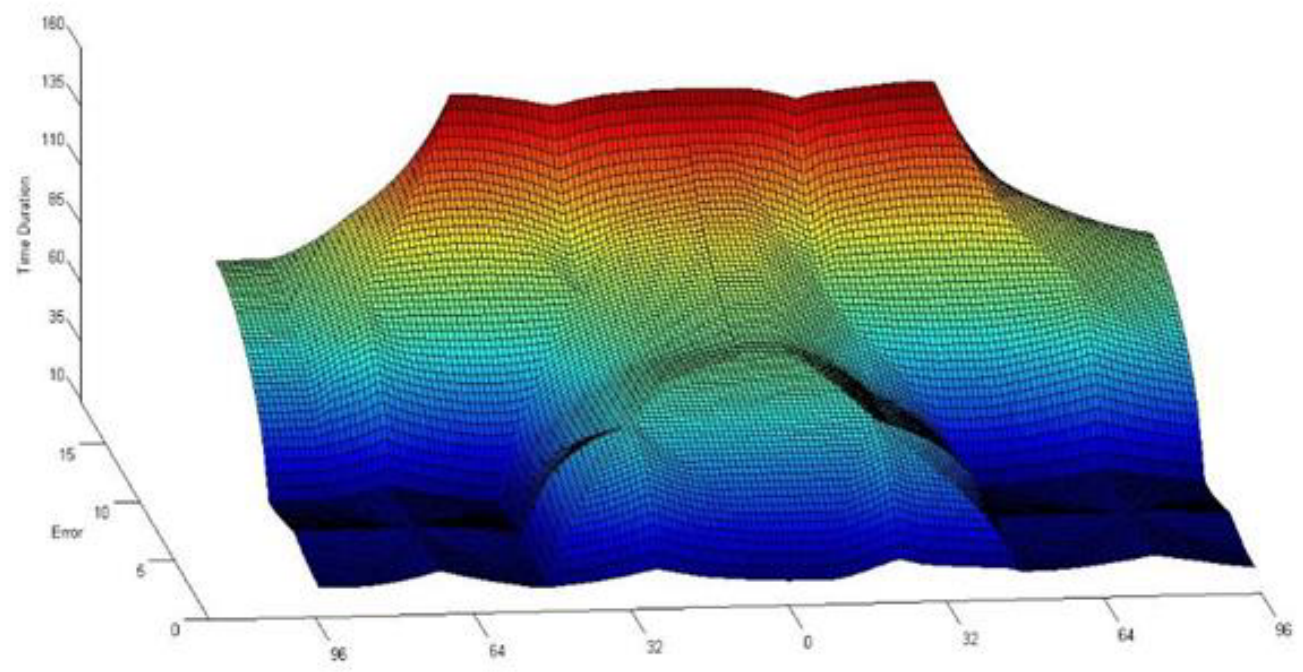

Figure 7: Control Surface (Basic T1FLC).

The comparisons and details for one specific two dimension curve of the control surface are shown in Figure 8.

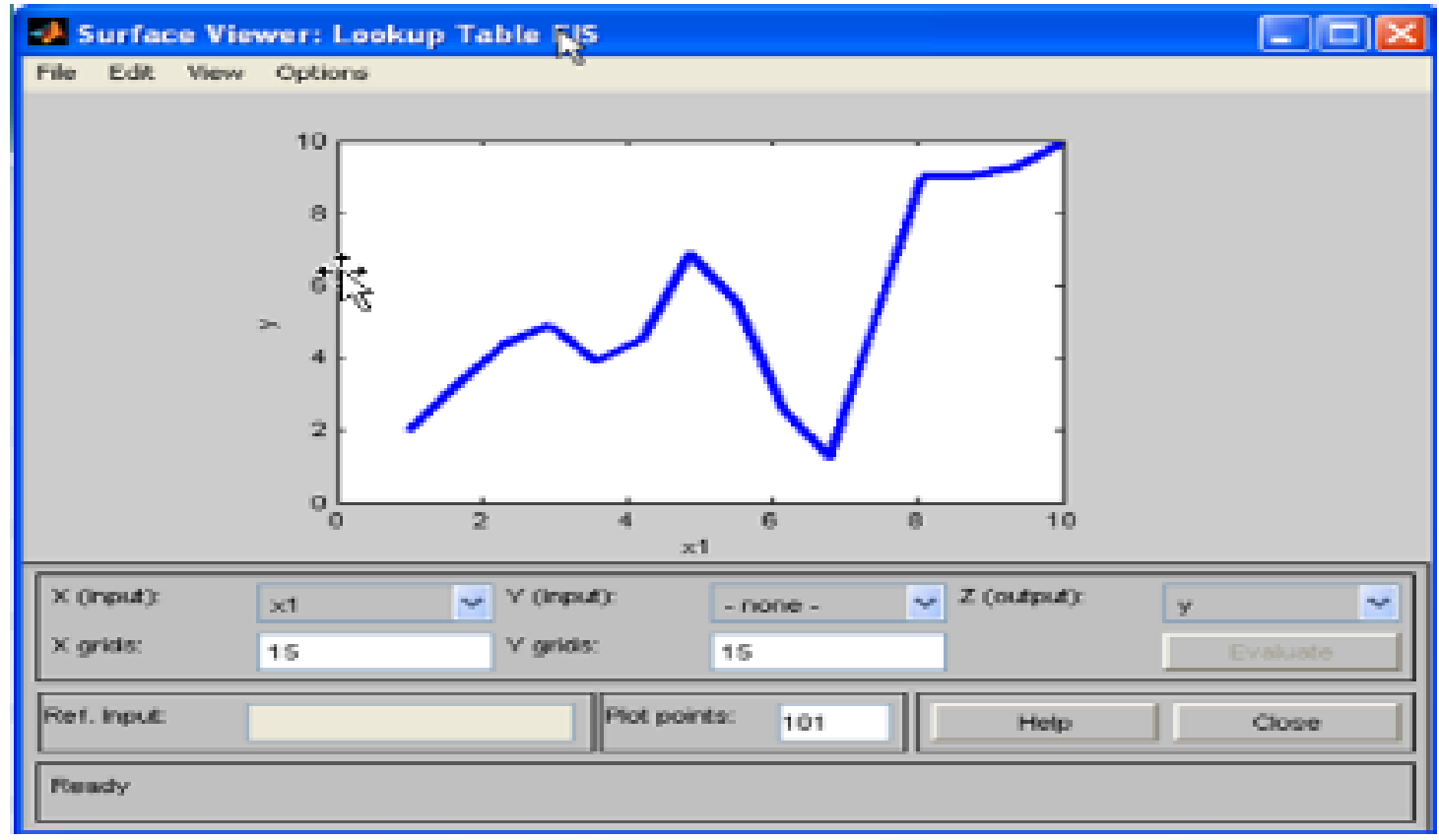

Figure 8: Error calculation. 
If Excel adds data from Excel 10 to data up to 84, then the result is displayed as shown below.

\section{Error chart}

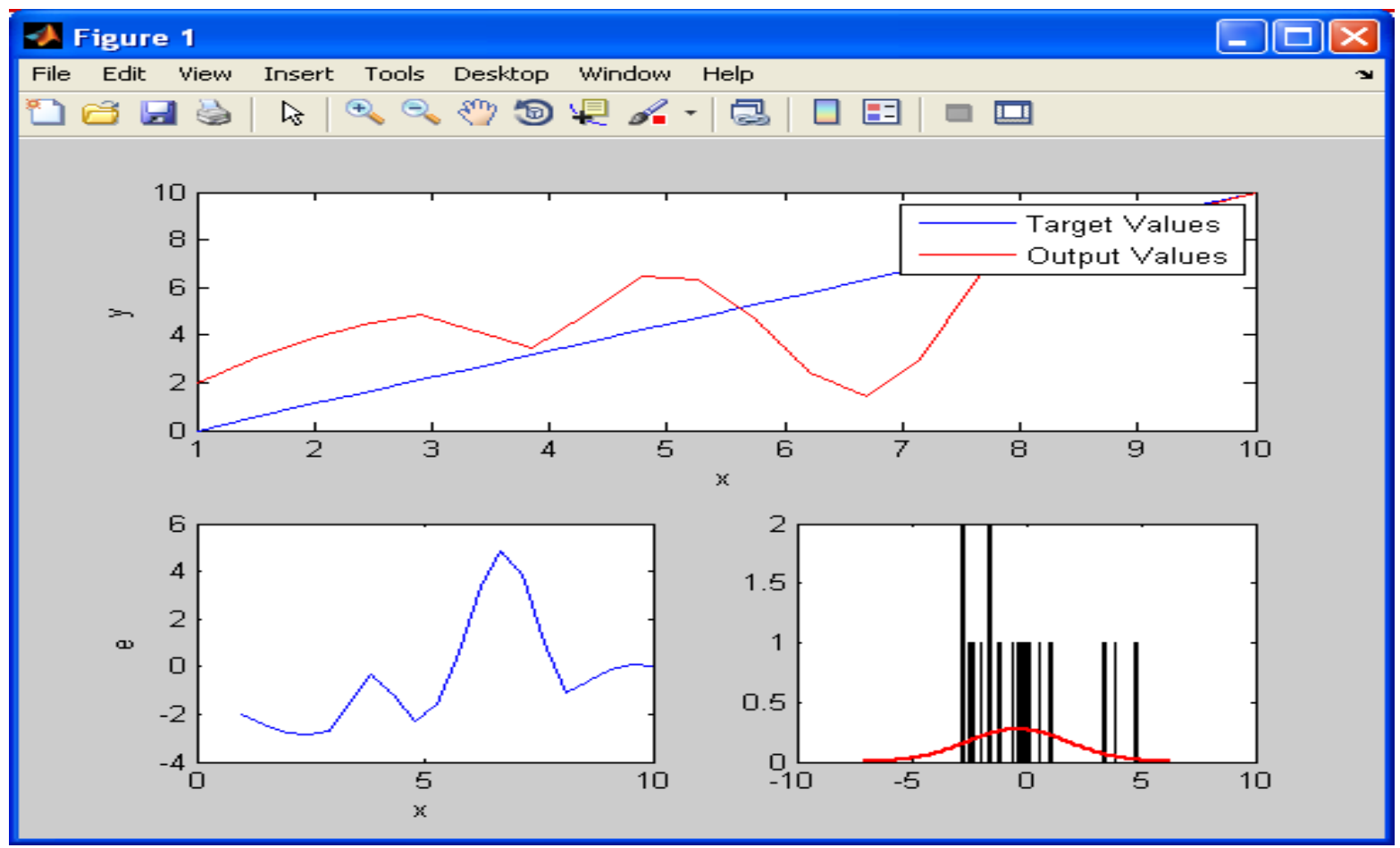

Figure 9: Error Curve

Simulating two inputs and an output system with 1000 data with a lot of data in the MATLAB

\begin{tabular}{|c|c|c|c|c|c|}
\hline 4 & A & B & C & D & $E$ \\
\hline 1 & -1.07026 & -1.9618 & -1.19612 & 0 & 9995.02 \\
\hline 2 & -1.12232 & -1.75082 & -1.30135 & 0 & 9995.025 \\
\hline 3 & -1.1279 & -1.33819 & -2.0261 & 0 & 9995.03 \\
\hline 4 & -1.1279 & -1.02534 & -2.05589 & 0 & 9995.035 \\
\hline 5 & -1.1279 & -0.76498 & -1.8958 & 0 & 9995.04 \\
\hline 6 & -1.1279 & -0.42623 & -2.07708 & 0 & 9995.045 \\
\hline 7 & -1.1279 & -0.03224 & -2.35183 & 0 & 9995.05 \\
\hline 8 & -1.1279 & 0.297018 & -2.27344 & 0 & 9995.055 \\
\hline 9 & -1.1279 & 0.65447 & -2.32823 & 0 & 9995.06 \\
\hline 10 & -1.1279 & 1.012345 & -2.35703 & 0 & 9995.065 \\
\hline 11 & -0.52077 & 1.448338 & -2.63183 & 0 & 9995.07 \\
\hline 12 & -0.30481 & 1.798873 & -2.48436 & 0 & 9995.075 \\
\hline 13 & -0.07781 & 2.125151 & -2.32978 & 0 & 9995.08 \\
\hline 14 & 0.12591 & 2.119393 & -1.1457 & 0 & 9995.085 \\
\hline 15 & 0.32709 & 2.297705 & -1.16722 & 0 & 9995.09 \\
\hline 16 & 0.489789 & 2.114077 & 0.028482 & 0 & 9995.095 \\
\hline 17 & 0.653828 & 2.290185 & -0.57278 & 0 & 9995.1 \\
\hline 18 & 0.783183 & 2.10738 & 0.322957 & 0 & 9995.105 \\
\hline 19 & 0.886204 & 1.97339 & 0.608111 & 0 & 9995.11 \\
\hline 20 & 0.961816 & 1.802327 & 0.874267 & 0 & 9995.115 \\
\hline 21 & 0.994049 & 1.444144 & 1.631076 & 0 & 9995.12 \\
\hline 22 & 1.012717 & 1.340729 & 1.160254 & 0 & 9995.125 \\
\hline 23 & 1.012717 & 0.940583 & 1.913947 & 0 & 9995.13 \\
\hline
\end{tabular}
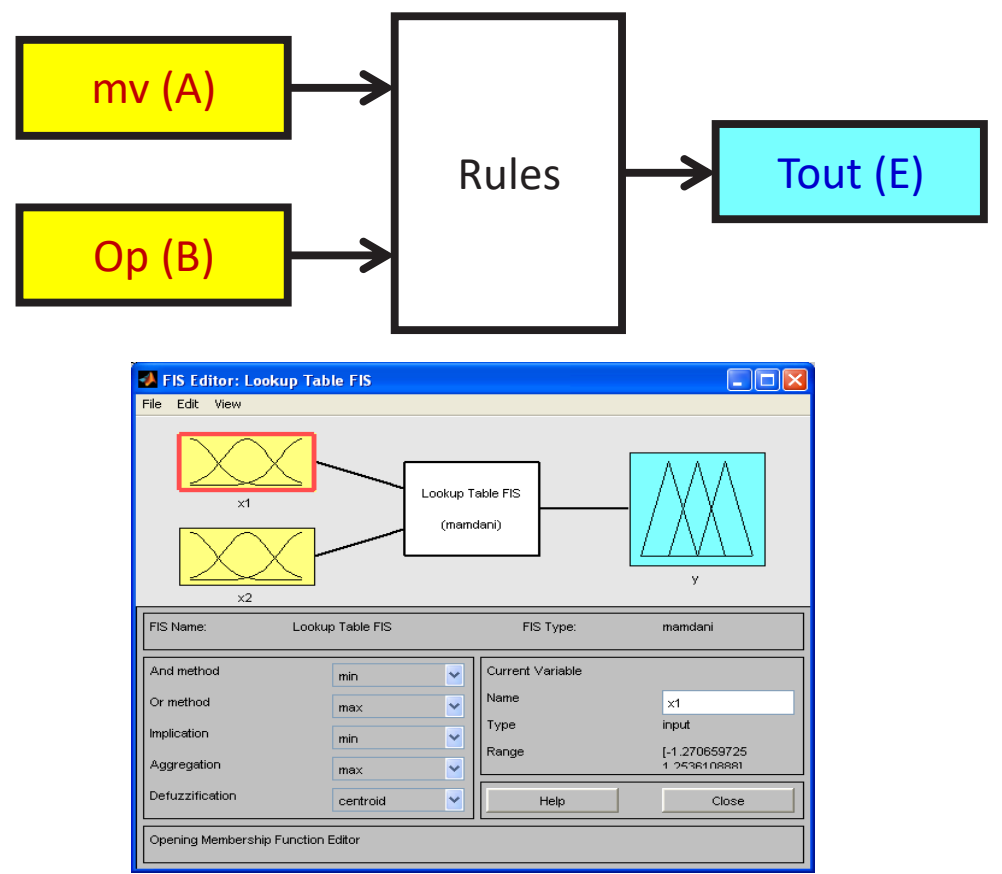

Figure 10: Input and Output graph with 10 membership members 


\section{Input and Output graph with 10 membership members}

The same problem is designed with 1000 real samples data with two inputs and one output and the same problem as 1000 data is tested with two inputs and one output with ANFIS.

The Proposed FLC has applied to steam room. Proposed controller because of realization with low number of rules provided lesser time of valve activation, low power consumption and much higher inference speed $\frac{(13)}{3}$. Moreover, proposed controller is much more accurate than expert-based controllers. Type one fuzzy controller undertaken has been analyzed with clustering modeling and fuzzy lookup table modeling. Steam temperatures and mass flow rates of room are the reciprocal effect on the maximum point of the entry of compressor $\stackrel{(14),}{, ~} \stackrel{(15)}{\text {. }}$ Maximum temperature is found to be smaller using look-up table fuzzy modeling analysis as compared to clustering modeling. Lesser times value opening is always desire in steaming room. So new approach of fuzzy modeling is better than the clustering modeling. It can establish more efficient control of the temperature. A look-up table fuzzy model has been developed to control the thermal performance of steaming room. Comparison of look-up table model and clustering model shows that look-up table model has better precision and lesser valve destruction. This model is giving lesser activation times of value for the same range of steam temperature and higher mass flow rate. Control based on look-up table fuzzy modeling will be more efficient as it improves the temperature at entry of steaming room. It is also evident that problems hard to be treated by PID modeling can be solved in the way of look-up table modeling with more ease.

Table 4: Comparison of proposed method with other applied methods.

\begin{tabular}{cccccc}
$\begin{array}{c}\text { Controller } \\
\text { Number }\end{array}$ & $\begin{array}{c}\text { Controller } \\
\text { Type }\end{array}$ & $\begin{array}{c}\text { Switching } \\
\text { Number }\end{array}$ & $\begin{array}{c}\text { Percentage of Time Duration that } \\
\text { Valve is Closed to Total Time }\end{array}$ & Emax & ERMS \\
1 & PID & 283 & $-10.6 \%$ & $-2.0^{\circ} \mathrm{C}$ & $+0.2^{\circ} \mathrm{C}$ \\
2 & T1 FLC & 203 & $-21 \%$ & $-4.8^{\circ} \mathrm{C}$ & $-3.1^{\circ} \mathrm{C}$ \\
3 & Proposed & 163 & $-6 \%$ & $-2.6^{\circ} \mathrm{C}$ & $-2.1^{\circ} \mathrm{C}$ \\
\hline
\end{tabular}

\section{CONCLUSION}

A look-up table fuzzy model applying novel control strategy proposed in this paper. It consists of fifteen if-then rules that extracted from real steaming rule data. The testing of the system confirms that extracted rules provides a rule-base which is define the system in an optimum way. The steps of lookup method to extracting rules using measured data pairs are presented. The effectiveness of model to simulate the steaming process curves and providing a well-defined system is verified. We applied this method to controlling the time duration of valve activation. Simulation results show that the generated fuzzy model system is capable of approximating steaming process function. It also shows that the activation times of valve can be greatly improved by selecting the longer intervals of time regions. 


\section{REFERENCES}

1. Aminifar, S. \&. b. M. A. Horizontal and vertical rule bases method in fuzzy controllers. Mathematical Problems in Engineering. 2013; http:// dx.doi.org/10.1155/2013/532046.

2. Aminifar, S. \&. b. M. A.. A novel fuzzy controller applicable to steaming room. s.l., Control System, Computing and Engineering (ICCSCE). IEEE International Conference. 2012; doi: 10.1109/ ICCSCE.2012.6487136.

3. Ye, X. Z. T. C. H. C. J. \&. C. J. Ye, X., Zhang, T., Chen, H., Cao, J., \& Chen, J. Fuzzy control of hydrogen pressure in fuel cell system.. International Journal of Hydrogen Energy. 2019 44(16), 84608466.

4. Daneshwar, M. A. \&. N. N. M. Identification of a process with control valve stiction using a fuzzy system: A data-driven approach. Journal of Process Control. 2014; 24(4), 249-260.

5. Li, Y. \&. W. Q. Adaptive robust tracking control of a proportional pressure-reducing valve with dead zone and hysteresis. Transactions of the Institute of Measurement and Control. 2018; 40(7), 2151-2166.

6. Aminifar, S. \&. M. A. Uncertainty in interval type-2 fuzzy systems. Mathematical Problems in Engineering. 2013; http://dx.doi. org/10.1155/2013/452780.

7. Castillo, O. \&. A.-A. L. A generalized type-2 fuzzy logic approach for dynamic parameter adaptation in bee colony optimization applied to fuzzy controller design. Information Sciences. 2018; 460, 476-496. https://doi.org/10.1016/j. ins.2017.10.032.

8. Ye, D. D. N. N. \&. Z. X. G. Fault-tolerant controller design for general polynomial-fuzzy-model-based systems. Transactions on Fuzzy Systems. 2018; 26(2), 1046-1051. doi: 10.1109/ TFUZZ.2017.2686819.

9. Ammar, H. H. A. A. T. T. T. D. T. K. \&. S. A. Design and implementation of fuzzy PID controller into multi agent smart library system prototype. Cham, Springer. 2018; 23-28. doi: 10.1007/9783-319-74690-6_13.
10. Wang, L. I. -. X. I. N. A course in'fuzzsystem and control. W35 ed. s.l.:Prentice-Hall International, Inc. 1997.

11. Zhou, Y. G. S. \&. C. F. J. Explore an evolutionary recurrent ANFIS for modelling multi-stepahead flood forecasts. Journal of Hydrology. 2019; 570, 343-355. https://doi.org/10.1016/i. ihydrol.2018.12.040.

12. Aminifar, S. Design and Implementation of Fuzzy Controllers for Handling Uncertainty in an Industrial Application. Doctoral dissertation, University Science Malaysia. 2014.

13. Daneshwar MA, Mohd Noh N. Detection of stiction in flow control loops based on fuzzy clustering. Control Engineering Practice. Elsevier BV; 2015; 39:23-34. http://dx.doi.org/10.1016/i. conengprac.2015.02.002.

14. Daneshwar, M. A. S. \&. Y. G. Hardware implementation of an adaptive mixed signal neuro fuzzy system using high speed and low power analog CMOS circuits. Journal of Basic and Applied Scientific Research. 2011; 1(10)1415-1422.

15. di Capaci, R. B. \&. S. C. An augmented PID control structure to compensate for valve Stiction. IFAC-PapersOnLine. 2018; 51(4), 799-804. https://doi.org/10.1016/j.ifacol.2018.06.181. 